\title{
Una nueva Convención de la UNESCO para la protección del patrimonio cultural subacuático
}

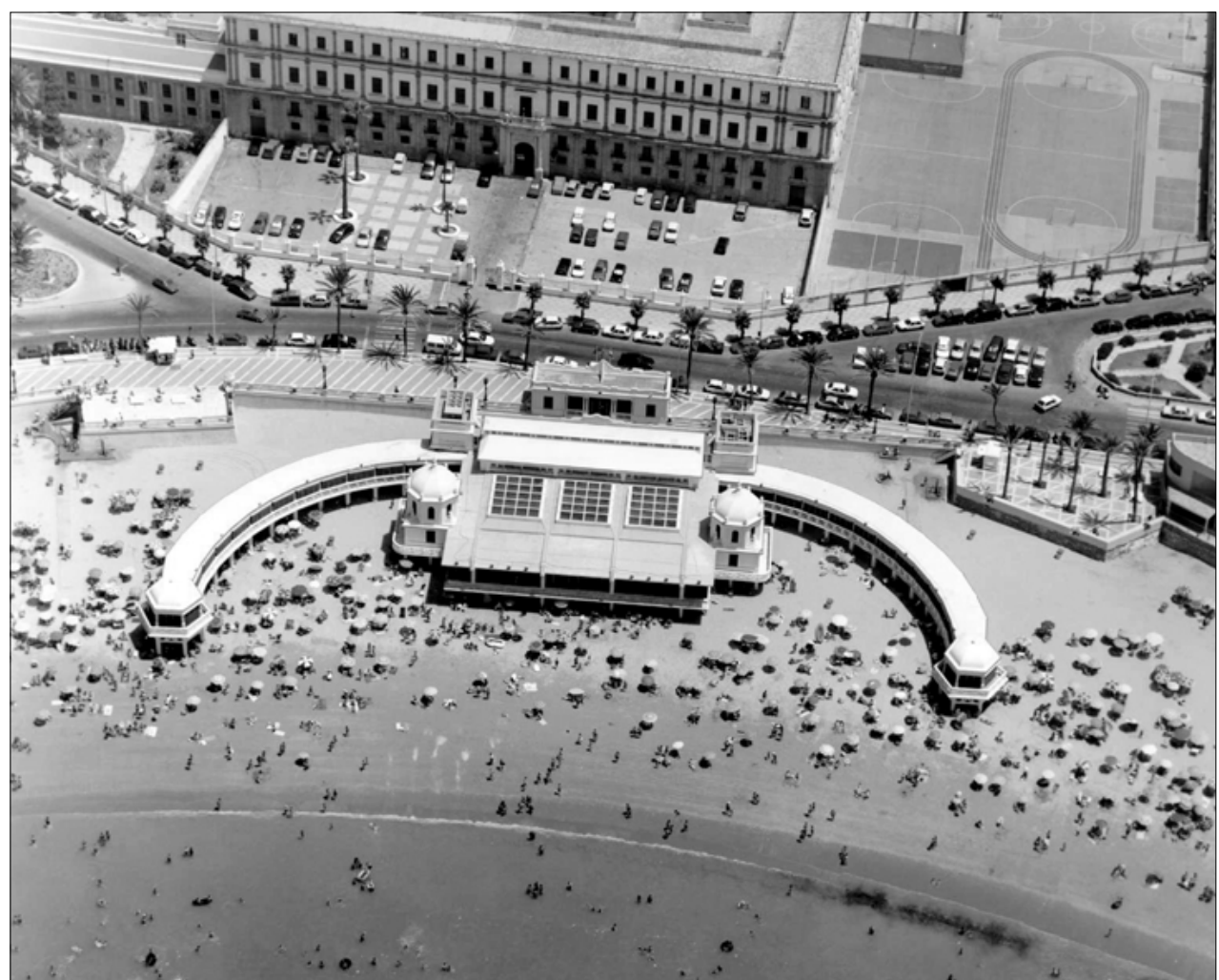

Vista aérea del Balneario de Nuestra Señora de la Palma y el Real (Cádiz). Sede del Centro de Arqueología Subacuática del Instituto Andaluz del Patrimonio Histórico

Carlos Alonso Villalobos

Instituto Andaluz del Patrimonio Histórico Centro de Arqueología Subacuática

\section{Resumen:}

La UNESCO ha aprobado recientemente una Convención para la protección del patrimonio cultural subacuático como respuesta al grave riesgo que para el mismo supone la actividad cada vez más extendida de los caza tesoros y la falta de una normativa internacional específica para el control de la misma.

Palabras claves:

Protección del patrimonio / Patrimonio cultural subacuático / UNESCO / Arqueología subacuática
El objeto de estas páginas es dar a conocer a los lectores el texto íntegro de la nueva Convención Internacional que, sobre la protección del patrimonio cultural subacuático, ratificó la UNESCO el pasado 2 de noviembre del 2001.

En el año 1999, en este mismo boletín', se publicaba un artículo ampliamente documentado en el que se recogía el proceso de gestación que llevó a la firma de la Carta Internacional sobre la Protección y Gestión del Patrimonio Cultural Subacuático (UNESCO, 1996), base sobre la que se apoya la nueva Convención. Permítannos por tanto remitirles al texto de aquel trabajo y volver, a su vez, sobre algunos aspectos allí tratados por considerarlo necesario para la correcta comprensión del texto que ahora nos ocupa.

El Patrimonio Cultural Subacuático constituye sin duda la parte mejor conservado de nuestro legado cultural. Sus valores históricos son insospechados, como ha quedado de manifiesto ante los recientes hallazgos de Pisa (Italia) o el Mar Negro, entre otros. Pero 
estos restos sumergidos de nuestro pasado se ven cada vez más amenazados por los intereses de los cazatesoros. Los grandes beneficios obtenidos tanto del expolio y la venta de los objetos arqueológicos, como de la producción de documentales o la prestación de servicios especializados para el rescate de pecios, son el objetivo principal de estas empresas de cazatesoros, muy especialmente cuando el objeto de expolio es uno de los múltiples galeones españoles o portugueses naufragados entre los siglos XVI y XVIII en aguas del Atlántico o el Pacífico Sur cargados con oro y plata 2 .

La invención del regulador por parte de Cousteau y Gagnan (1943) supuso, además del nacimiento del buceo deportivo autónomo, el desarrollo de nuevas disciplinas científicas con técnicas y metodología adaptada para trabajar en el medio hiperbárico (entre ellas la arqueología subacuática). Pero la popularización del uso del mismo ha tenido unas consecuencias indirectas nefastas para la conservación del patrimonio cultural subacuático. Entre los años 60 y 80 del pasado siglo se produjo el arrasamiento de muchos de los pecios de la antigüedad que yacían desde hacía miles de años en aguas del Mediterráneo. La falta de concienciación respecto a los valores e importancia de este patrimonio cultural (tanto a nivel social como de Estado); la desprotección legal del mismo; el expolio practicado por muchos buceadores deportivos; y las intervenciones de algunos arqueólogos que (con ayuda de buzos) siguieron practicando el rescate de piezas arqueológicas en vez de el método arqueológico subacuático, fueron circunstancias que llevaron a la destrucción a muchos de los yacimientos situados por encima de los 40 metros de profundidad, cota hasta la que era viable la inmersión con los medios de la época.

El gran desarrollo tecnológico de los últimas décadas y su aplicación a la explotación de los recursos marinos (incluso a altas profundidades) ha vuelto a poner de actualidad esta dramática realidad vivida años atrás. Experiencias como las del Titanic muestran hasta donde puede llegar el afán del ser humano cuando existen medios técnicos e intereses para ello. Por su parte, casos como los del norteamericano Mel Fisher, convertido en multimillonario gracias al expolio del galeón español Nuestra Señora de Atocha, hundido en 1622 en aguas de Florida; o situaciones como la obtención de altos beneficios económicos de la venta de objetos procedentes de este tipo de actuaciones ${ }^{3}$ por parte de las compañías de subastas, nos ilustran sobre el alto interés que para algunos tiene la localización y el rescate de los "tesoros" que los antiguos galeones transportaban en sus bodegas, a costa, eso sí, de la perdida y destrucción de los valores históricos de estos pecios, tema al parecer que ni comprenden, ni les interesa.

Nuestra legislación, como la de muchos países, protege al patrimonio cultural sumergido ante este tipo de intervenciones $y$, hasta el presente, a pesar de los múltiples proyectos presentados por empresas que sólo buscan fines "altruistas", no se ha concedido nin-

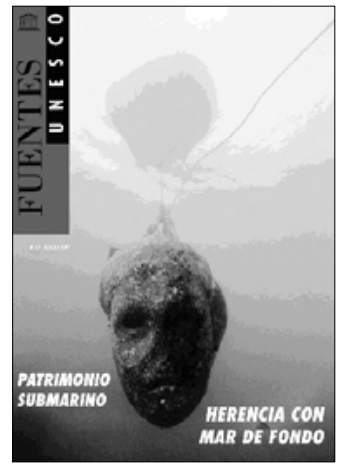

gún tipo de autorización para localizar y rescatar (por ejemplo) alguno de los múltiples galeones que, cargados con oro y plata, naufragaron en nuestras aguas a la vuelta de sus viajes a las Américas (único objetivo que, al parecer, atrae a gran parte de los aventureros o aficionados que se declaran protectores de nuestro patrimonio).

Las medidas para poder luchar contra este problema sin embargo son complejas y pasan principalmente por una modificación del marco jurídico en el que, se encuadran las autorizaciones concedidas a los cazatesoros, aprovechando el vacío de algunas legislaciones de cultura.

En 1958 la soberanía de los estados costeros sobre sus aguas sólo llegaba hasta el límite de las 3 millas, en 1982; tras la celebración de dos grandes conferencias internacionales en materia de derecho marítimo (la de Ginebra de 1958, y la Tercera Conferencia de las Naciones Unidas -UNCLOS III- que culminó en 1982), y ante el fuerte desarrollo técnico experimentado en la explotación de los recursos marinos, los organismos internacionales se vieron obligados a buscar fórmulas para que los estados costeros pudieran sancionar a los cazatesoros que actuaran en la zona contigua a sus aguas nacionales, incluso hasta el límite de las 24 millas.

Uno de los principales caballos de batalla en todo este entramado legal es el de la propiedad de los pecios. Parece admitido internacionalmente que aquellos que se encuentran en aguas territoriales pertenecen al país que ejerce la soberanía sobre esas aguas. Pero ¿qué sucede con los que se encuentran fuera de este límite?

En 1988 fue localizado a 160 millas marinas de las costas de Carolina del Sur y a 2.400 metros de profundidad, los restos del Central America, un barco que naufragó en 1857 transportando un cargamento de oro valorado en I millón de dólares. Cuando parte de su carga fue rescatada, treinta y una compañías de seguro británicas y norteamericanas que indemnizaron a los afectados tras el naufragio reclamaron su propiedad ante los tribunales. Casos similares se han repetido en todo el mundo con final diferente. En unas ocasiones los tribunales han dado la razón a los rescatadores, considerando que el barco había sido objeto de abandono por parte de sus antiguos propietarios desde el accidente; en otras, los jueces con- 
sideraron que los propietarios legales no pierden sus derechos de propiedad con el paso de los siglos, salvo que haya habido expresa renuncia a la misma. El derecho de propiedad se hace aún más complejo en el caso de los pecios militares, para los que muchos estados piden inmunidad soberana a pesar de encontrarse hundidos en aguas de otros países. Uno de estos ejemplos es el de los restos de la fragata española Juno, hundida en 1802 en aguas de Virginia y localizada por Ben Benson, millonario norteamericano convertido en cazatesoros. El tribunal federal de Norfolk (Virginia) dio en esta ocasión la razón al Estado español, reconociendo sus derechos sobre el pecio como propietario exclusivo del mismo.

Con el fin de poner claridad y ayudar a normalizar esta compleja problemática, la UNESCO, la Sección de Asuntos Jurídicos de la División de Océanos y de Derecho del Mar de la ONU y la Organización Marítima Internacional, han venido trabajando a lo largo de los últimos años sobre la base de un texto presentado por la Asociación de Derecho Internacional.

Ya en 1996, en la denominada Carta de Sofía del Consejo Internacional de Monumentos y Sitios (ICOMOS), se recogían los principios fundamentales que debían regir cualquier intervención que se realizara sobre los bienes culturales que conforman el patrimonio cultural subacuático. Reproducida casi en su totalidad en la nueva Convención, la Carta suponía sentar las bases para una correcta gestión y protección del patrimonio cultural sumergido. Su filosofía era luchar contra la destrucción material de este patrimonio y la comercialización de sus bienes, práctica desgraciadamente cada vez más extendida; para ello, entre sus principios generales (Artículo I de la Carta), recomendaba como medidas prioritarias la conservación "in situ" y el empleo de técnicas no destructivas (principalmente de documentación, prospección y muestreo) para el estudio de estos bienes.

Durante los últimos cuatro años unos 350 expertos de más de 90 países han continuado trabajando en esta línea hasta llegar a la redacción la recién aprobada Convención sobre la Protección del Patrimonio Cultural Subacuático.

Los puntos más debatidos durante las diferentes reuniones de la Convención fueron principalmente tres:

- la inmunidad de los buques de guerra

- la jurisdicción de los estados costeros sobre la zona económica exclusiva y la plataforma continental

- los fines que deben perseguir las intervenciones que se realice sobre los bienes de este patrimonio

España, junto con Francia, el Reino Unido y Turquía se convirtieron en los máximos defensores a la hora de reclamar la soberanía sobre los buques de guerra hundidos en aguas jurisdiccionales de otros países.
Frente a ellos, todos los países latinoamericanos y caribeños, Arabia Saudí y Corea del Sur reclamaban como parte de su patrimonio esos pecios. La Convención, desde la perspectiva jurídica, ratifica la soberanía de los Estados costeros sobre los bienes del patrimonio cultural subacuático que se localice tanto en aguas de la Zona Económica Exclusiva como en la Plataforma Continental (entre las 12 y las 200 millas) sea cual sea su naturaleza. No obstante, cuando los restos localizados correspondan a un antiguo buque de guerra de otro país, estos deberán informar y consultar al titular de su pabellón, sin cuya autorización no podrán intervenir. Dentro de la zona de las 12 millas, tan sólo se deberá informar al país titular del pabellón del barco; mientras que en caso de que el hallazgo se produzca en aguas interiores de un país, este no tendrá necesidad de comunicarlo en ningún caso. Finalmente, si el pecio se localiza en aguas internacionales, la soberanía del país del pabellón del buque primará sobre las demás.

Quizás lo más interesante de esta Convención es el compromiso general de proteger y conservar in situ los yacimientos, prohibiéndose actuaciones no científicas sobre los mismos y la comercialización de las piezas de procedencia subacuáticas cuya recuperación no se haya realizado con métodos de investigación científica. De cumplirse las recomendaciones, este sería sin duda su mayor logro dado que supone la desaprobación oficial de la práctica del rescate efectuada por las empresas de cazatesoros y la lucha contra el comercio de objetos procedentes de estas actuaciones.

A lo largo de las negociaciones, España, el país que ha presentado una postura más radical respecto a la soberanía de sus antiguos pecios en aguas de otros, ha visto truncada gran parte de sus expectativas iniciales. Desde el 2 de noviembre hemos perdido para siempre los derechos sobre gran parte de ese patrimonio cultural cuyo conocimiento y estudio suponen muchas páginas de nuestra historia naval. Para algunos esta pérdida se traduce en la renuncia a los miles de millones en oro, plata y joyas que transportaban esos barcos en sus bodegas. Para otros la negociación ha servido para acabar con los cazatesoros y preservar el patrimonio cultural subacuático para el futuro. El tiempo dirá la valía y alcance de lo acordado. Pero mientras, los Estados deben velar para que el espíritu de la Convención se cumpla trabajando para: integrar el patrimonio cultural sumergido de manera directa y efectiva en los programas y directrices culturales; promover proyectos para que se conozca su verdadero potencial; diseñar estrategias para su protección legal y material frente al expolio; buscar formulas para que se minimicen los riesgos que sobre el mismo suponen las intervenciones humanas sobre el litoral;.... y promover, por medio de la colaboración internacional, medidas para luchar contra esa moderna piratería que saquea y destruye nuestros viejos galeones, hoy, más que nunca, reconocidos como parte del Patrimonio de la Humanidad. 


\section{CONVENCIÓN SOBRE LA PROTECCIÓN DEL PATRIMONIO CULTURAL SUBACUÁTICO*}

\section{UNESCO}

París, 2 de noviembre de 200 I

La Conferencia General de la Organización de las Naciones Unidas para la Educación, la Ciencia y la Cultura, en su $3 I^{a}$ reunión, celebrada en París del I 5 de octubre al 3 de noviembre de 200 I,

Reconociendo la importancia del patrimonio cultural subacuático como parte integrante del patrimonio cultural de la humanidad y elemento de particular importancia en la historia de los pueblos, las naciones y sus relaciones mutuas en lo concerniente a su patrimonio común,

Consciente de la importancia de proteger y preservar ese patrimonio cultural subacuático y de que la responsabilidad de esa tarea incumbe a todos los Estados,

Observando el creciente interés y aprecio del público por el patrimonio cultural subacuático,

Convencida de la importancia que la investigación, la información y la educación tienen para la protección y preservación del patrimonio cultural subacuático,

Convencida de que el público tiene derecho a gozar de los beneficios educativos y recreativos que depara un acceso responsable y no perjudicial al patrimonio cultural subacuático in situ y de que la educación del público contribuye a un mejor conocimiento, aprecio y protección de ese patrimonio,

Consciente de que el patrimonio cultural subacuático se ve amenazado por actividades no autorizadas dirigidas a dicho patrimonio y de la necesidad de medidas más rigurosas para impedir esas actividades,

Consciente de la necesidad de dar una respuesta adecuada al posible impacto negativo en el patrimonio cultural subacuático de actividades legítimas que puedan afectarlo de manera fortuita,

Profundamente preocupada por la creciente explotación comercial del patrimonio cultural subacuático y, especialmente, por ciertas actividades que tienen por objetivo la venta, la adquisición o el trueque de patrimonio cultural subacuático,

Consciente de la disponibilidad de tecnología de punta que facilita el descubrimiento del patrimonio cultural subacuático y el acceso al mismo,

Convencida de que la cooperación entre los Estados, organizaciones internacionales, instituciones científicas, organizaciones profesionales, arqueólogos, buzos, otras partes interesadas y el público en general es esencial para proteger el patrimonio cultural subacuático,
Considerando que la prospección, extracción y protección del patrimonio cultural subacuático, además de un alto grado de especialización profesional, requiere un acceso a métodos científicos especiales y la aplicación de éstos, así como el empleo de técnicas y equipos adecuados, para todo lo cual se necesitan criterios rectores uniformes,

Consciente de la necesidad de codificar y desarrollar progresivamente normas relativas a la protección y la preservación del patrimonio cultural subacuático conformes con el derecho y la práctica internacionales, comprendidas la Convención sobre las Medidas que Deben Adoptarse para Prohibir e Impedir la Importación, la Exportación y la Transferencia de Propiedad llícitas de Bienes Culturales, aprobada por la UNESCO el 14 de noviembre de 1970, la Convención para la Protección del Patrimonio Mundial, Cultural y Natural, aprobada por la UNESCO el 16 de noviembre de 1972 y la Convención de las Naciones Unidas sobre el Derecho del Mar, de 10 de diciembre de 1982, Resuelta a mejorar la eficacia de las medidas adoptadas en el ámbito internacional, regional y nacional con objeto de preservar in situ el patrimonio cultural subacuático o, de ser necesario para fines científicos 0 para su protección, de proceder cuidadosamente a la recuperación del mismo,

Habiendo decidido, en su $29^{a}$ reunión, que esta cuestión sería objeto de una convención internacional,

Aprueba el día 2 de noviembre de 200 I, la presente Convención.

\section{Artículo I. Definiciones}

A los efectos de la presente Convención:

I. a) Por "patrimonio cultural subacuático" se entiende todos los rastros de existencia humana que tengan un carácter cultural, histórico o arqueológico, que hayan estado bajo el agua, parcial o totalmente, de forma periódica o continua, por lo menos durante 100 años, tales como:

i) los sitios, estructuras, edificios, objetos y restos humanos, junto con su contexto arqueológico y natural;

ii) los buques, aeronaves, otros medios de transporte o cualquier parte de ellos, su cargamento u otro contenido, junto con su contexto arqueológico y natural; $y$

iii) los objetos de carácter prehistórico.

b) No se considerará patrimonio cultural subacuático a los cables y tuberías tendidos en el fondo del mar.

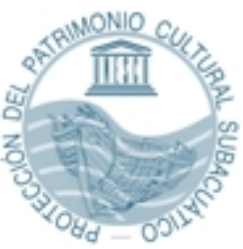

\footnotetext{
* El texto en castellano de la Convención ha sido extraído de la página de la Web que la UNESCO dedica al patrimonio cultural subacuático.
} 
0
0
$+\pi$
2
0
0
0
2
0
0
0
0
0
0
0
2
2
0
1
$<$

c) No se considerará patrimonio cultural subacuático a las instalaciones distintas de los cables y tuberías colocadas en el fondo del mar y todavía en uso.

2. a) Por "Estados Partes" se entiende los Estados que hayan consentido en obligarse por esta Convención y respecto de los cuales esta Convención esté en vigor.

b) Esta Convención se aplicará mutatis mutandis a los territorios mencionados en el apartado b) del párrafo 2 del Artículo 26 que lleguen a ser Partes en esta Convención de conformidad con los requisitos definidos en ese párrafo; en esa medida, el término "Estados Partes" se refiere a esos territorios.

3. Por "UNESCO" se entiende la Organización de las Naciones Unidas para la Educación, la Ciencia y la Cultura.

4. Por "Director General" se entiende el Director General de la UNESCO.

5. Por "Zona" se entiende los fondos marinos y oceánicos y su subsuelo fuera de los límites de la jurisdicción nacional.

6. Por "actividades dirigidas al patrimonio cultural subacuático" se entiende las actividades cuyo objeto primordial sea el patrimonio cultural subacuático y que puedan, directa o indirectamente, alterarlo materialmente o causarle cualquier otro daño.

7. Por "actividades que afectan de manera fortuita al patrimonio cultural subacuático" se entiende las actividades que, a pesar de no tener al patrimonio cultural subacuático como objeto primordial o secundario puedan alterarlo materialmente o causarle cualquier otro daño.

8. Por "buques y aeronaves de Estado" se entiende los buques de guerra y otros navíos o aeronaves pertenecientes a un Estado o utilizados por él y que, en el momento de su hundimiento, fueran utilizados únicamente para un servicio público no comercial, que sean identificados como tales y que correspondan a la definición de patrimonio cultural subacuático.

9. Por "Normas" se entiende las Normas relativas a las actividades dirigidas al patrimonio cultural subacuático, tal y como se mencionan en el Artículo 33 de la presente Convención.

\section{Artículo 2. Objetivos y principios generales}

I. La presente Convención tiene por objeto garantizar y fortalecer la protección del patrimonio cultural subacuático.

2. Los Estados Partes cooperarán en la protección del patrimonio cultural subacuático.

3. Los Estados Partes preservarán el patrimonio cultu- ral subacuático en beneficio de la humanidad, de conformidad con lo dispuesto en esta Convención.

4. Los Estados Partes, individual o conjuntamente, según proceda, adoptarán todas las medidas adecuadas conformes con esta Convención y con el derecho internacional que sean necesarias para proteger el patrimonio cultural subacuático, utilizando a esos efectos, en función de sus capacidades, los medios más idóneos de que dispongan.

5. La preservación in situ del patrimonio cultural subacuático deberá considerarse la opción prioritaria antes de autorizar o emprender actividades dirigidas a ese patrimonio.

6. El patrimonio cultural subacuático recuperado se depositará, guardará y gestionará de tal forma que se asegure su preservación a largo plazo.

7. El patrimonio cultural subacuático no será objeto de explotación comercial.

8. De conformidad con la práctica de los Estados y con el derecho internacional, incluida la Convención de las Naciones Unidas sobre el Derecho del Mar, nada de lo dispuesto en esta Convención se interpretará en el sentido de modificar las normas de derecho internacional y la práctica de los Estados relativas a las inmunidades soberanas o cualquiera de los derechos de un Estado respecto de sus buques y aeronaves de Estado.

9. Los Estados Partes velarán por que se respeten debidamente los restos humanos situados en las aguas marítimas.

I 0.Un acceso responsable y no perjudicial del público al patrimonio cultural subacuático in situ, con fines de observación o documentación, deberá ser alentado para favorecer la sensibilización del público a ese patrimonio así como el reconocimiento y la protección de éste, salvo en caso de que ese acceso sea incompatible con su protección y gestión.

| | .Ningún acto o actividad realizado en virtud de la presente Convención servirá de fundamento para alegar, oponerse o cuestionar cualquier reivindicación de soberanía o jurisdicción nacional.

Artículo 3 . Relación entre la presente Convención y la Convención de las Naciones Unidas sobre el Derecho del Mar

Nada de lo dispuesto en esta Convención menoscabará los derechos, la jurisdicción ni las obligaciones que incumben a los Estados en virtud del derecho internacional, incluida la Convención de las Naciones Unidas sobre el Derecho del Mar. La presente Convención se interpretará y aplicará en el contexto de las disposiciones del derecho internacional, incluida la Convención de las Naciones Unidas sobre el Derecho del Mar, y de conformidad con ellas. 


\section{Artículo 4. Relación con las normas sobre salvamento y hallazgos}

Ninguna actividad relacionada con el patrimonio cultural subacuático a la que se aplica la presente Convención estará sujeta a las normas sobre salvamento y hallazgos, a no ser que:

a) esté autorizada por las autoridades competentes, y

b) esté en plena conformidad con la presente Convención, y

c) asegure que toda operación de recuperación de patrimonio cultural subacuático se realice con la máxima protección de éste.

\section{Artículo 5. Actividades que afectan de manera fortuita al} patrimonio cultural subacuático

Cada Estado Parte empleará los medios más viables de que disponga para evitar o atenuar cualquier posible repercusión negativa de actividades bajo su jurisdicción que afecten de manera fortuita al patrimonio cultural subacuático.

Artículo 6 - Acuerdos bilaterales, regionales u otros acuerdos multilaterales

I. Se alentará a los Estados Partes a celebrar acuerdos bilaterales, regionales $\mathrm{u}$ otros acuerdos multilaterales, o a perfeccionar los acuerdos existentes, con objeto de preservar el patrimonio cultural subacuático. Todos esos acuerdos deberán estar en plena conformidad con las disposiciones de la presente Convención y no menoscabar el carácter universal de ésta. En el marco de esos acuerdos, los Estados Partes podrán adoptar normas y reglamentos que aseguren una mejor protección del patrimonio cultural subacuático que los adoptados en virtud de la presente Convención.

2. Las Partes en esos acuerdos bilaterales, regionales 4 otros acuerdos multilaterales podrán invitar a adherirse a esos acuerdos a los Estados que tengan un vínculo verificable, en especial de índole cultural, histórica o arqueológica, con el patrimonio cultural subacuático de que se trate.

3. La presente Convención no modificará los derechos ni las obligaciones en materia de protección de buques sumergidos que incumban a los Estados Partes en virtud de otros acuerdos bilaterales, regionales $u$ otros acuerdos multilaterales, concertados antes de la aprobación de la presente Convención, máxime si están en conformidad con los objetivos de ésta.

Artículo 7. Patrimonio cultural subacuático en aguas interiores, aguas archipelágicas y mar territorial

I. En el ejercicio de su soberanía, los Estados Partes tienen el derecho exclusivo de reglamentar y autori- zar las actividades dirigidas al patrimonio cultural subacuático en sus aguas interiores, aguas archipelágicas y mar territorial.

2. Sin perjuicio de otros acuerdos internacionales y normas de derecho internacional aplicables a la protección del patrimonio cultural subacuático, los Estados Partes exigirán que las Normas se apliquen a las actividades dirigidas al patrimonio cultural subacuático situado en sus aguas interiores, aguas archipelágicas y mar territorial.

3. En sus aguas archipelágicas y mar territorial, en el ejercicio de su soberanía y de conformidad con la práctica general observada entre los Estados, con miras a cooperar sobre los mejores métodos de protección de los buques y aeronaves de Estado, los Estados Partes deberían informar al Estado del pabellón Parte en la presente Convención y, si procede, a los demás Estados con un vínculo verificable, en especial de índole cultural, histórica o arqueológi$\mathrm{ca}$, del descubrimiento de tales buques y aeronaves de Estado que sean identificables.

\section{Artículo 8. Patrimonio cultural subacuático en la zona} contigua

Sin perjuicio de lo dispuesto en los Artículos 9 y 10 y con carácter adicional a lo dispuesto en los mismos y de conformidad con el párrafo 2 del Artículo 303 de la Convención de las Naciones Unidas sobre el Derecho del Mar, los Estados Partes podrán reglamentar y autorizar las actividades dirigidas al patrimonio cultural subacuático en su zona contigua. Al hacerlo, exigirán que se apliquen las Normas.

\section{Artículo 9. Información y notificación en la zona económi- ca exclusiva y en la plataforma continental}

I. Todos los Estados Partes tienen la responsabilidad de proteger el patrimonio cultural subacuático en la zona económica exclusiva y en la plataforma continental de conformidad con la presente Convención.

\section{En consecuencia:}

a) Un Estado Parte exigirá que cuando uno de sus nacionales o un buque que enarbole su pabellón descubra patrimonio cultural subacuático situado en su zona económica exclusiva o en su plataforma continental o tenga la intención de efectuar una actividad dirigida a dicho patrimonio, el nacional o el capitán del buque le informe de ese descubrimiento o actividad.

b) En la zona económica exclusiva o en la plataforma continental de otro Estado Parte:

i) los Estados Partes exigirán que el nacional o el capitán del buque les informe e informe al otro Estado Parte de ese descubrimiento o actividad;

ii) alternativamente un Estado Parte exigirá que el nacional o el capitán del buque le informe de ese

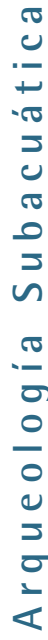

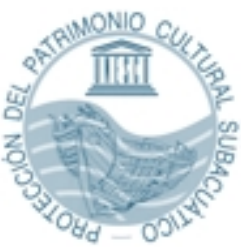


escubrimiento o actividad y asegurará la transmisión rápida y eficaz de esa información a todos los demás Estados Partes.

2. Al depositar su instrumento de ratificación, aceptación, aprobación o adhesión, un Estado Parte declarará la forma en que transmitirá la información prevista en el apartado b) del párrafo I del presente artículo.

3. Un Estado Parte notificará al Director General los descubrimientos $\mathrm{O}$ actividades dirigidas al patrimonio cultural subacuático que sean puestos en su conocimiento en virtud del párrafo I del presente artículo.

4. El Director General comunicará sin demora a todos los Estados Partes cualquier información que le sea notificada en virtud del párrafo 3 del presente artículo.

5. Todo Estado Parte podrá declarar al Estado Parte en cuya zona económica exclusiva o en cuya plataforma continental esté situado el patrimonio cultural subacuático, su interés en ser consultado sobre cómo asegurar la protección efectiva de ese patrimonio. Esa declaración deberá fundarse en un vínculo verificable, en especial de índole cultural, histórica o arqueológica, con el patrimonio cultural subacuático de que se trate.

Artículo 10. Protección del patrimonio cultural subacuático en la zona económica exclusiva y en la plataforma continental

I. No se concederá autorización alguna para una actividad dirigida al patrimonio cultural subacuático situado en la zona económica exclusiva o en la plataforma continental, salvo lo dispuesto en el presente artículo.

2. Un Estado Parte en cuya zona económica exclusiva o en cuya plataforma continental esté situado el patrimonio cultural subacuático tiene derecho a prohibir o a autorizar cualquier actividad dirigida a este patrimonio para impedir cualquier intromisión en sus derechos soberanos o su jurisdicción reconocidos por el derecho internacional, incluida la Convención de las Naciones Unidas sobre el Derecho del Mar.

3. Cuando tenga lugar un descubrimiento de patrimonio cultural subacuático situado en la zona económica exclusiva o en la plataforma continental de un Estado Parte, o se tenga la intención de efectuar una actividad dirigida a dicho patrimonio cultural subacuático, ese Estado Parte:

a) consultará a todos los demás Estados Partes que hayan declarado un interés en virtud del párrafo 5 del Artículo 9 sobre la mejor manera de proteger el patrimonio cultural subacuático;

b) coordinará esas consultas como "Estado Coordinador", a menos que declare expresamente que no desea hacerlo, caso en el cual los Estados Partes que hayan declarado un interés en virtud del párrafo 5 del Artículo 9 designarán a un Estado Coordinador.

4. Sin perjuicio de la obligación de todos los Estados Partes de proteger el patrimonio cultural subacuático mediante la adopción de todas las medidas viables conformes al derecho internacional, con el fin de impedir todo peligro inmediato para el patrimonio cultural subacuático, incluido el saqueo, el Estado Coordinador podrá adoptar todas las medidas viables y/o conceder cualquier autorización que resulte necesaria de conformidad con la presente Convención y, de ser necesario, con anterioridad a las consultas, con el fin de impedir cualquier peligro inmediato para el patrimonio cultural subacuático, ya sea ocasionado por la actividad humana o por cualquier otra causa, incluido el saqueo. Al adoptar tales medidas se podrá solicitar la asistencia de otros Estados Partes.

\section{El Estado Coordinador:}

a) pondrá en práctica las medidas de protección que hayan sido acordadas por los Estados que participen en la consulta, que incluyen al Estado Coordinador, a menos que los Estados que participen en la consulta, que incluyen al Estado Coordinador, acuerden que otro Estado Parte pondrá en práctica esas medidas;

b) expedirá todas las autorizaciones necesarias con respecto a las medidas así acordadas de conformidad con las Normas, a menos que los Estados que participen en la consulta, que incluyen al Estado Coordinador, acuerden que otro Estado Parte expedirá esas autorizaciones;

c) podrá realizar toda investigación preliminar que resulte necesaria en el patrimonio cultural subacuático y expedirá todas las autorizaciones necesarias a tal fin, y transmitirá sin demora los resultados de tal investigación al Director General quien, a su vez, comunicará esas informaciones sin demora a los demás Estados Partes.

6. Al coordinar las consultas, adoptar medidas, realizar una investigación preliminar y/o expedir autorizaciones en virtud del presente artículo, el Estado Coordinador actuará en nombre de los Estados Partes en su conjunto y no en su interés propio. Esta acción en sí no podrá ser invocada para reivindicar derecho preferente o jurisdiccional alguno que no esté reconocido por el derecho internacional, incluida la Convención de las Naciones Unidas sobre el Derecho del Mar.

7. A reserva de lo dispuesto en los párrafos 2 y 4 del presente artículo, no se efectuará ninguna actividad dirigida a un buque o aeronave de Estado sin el acuerdo del Estado del pabellón y la colaboración del Estado Coordinador.

\section{Artículo II. Información y notificación en la Zona}

I. Todos los Estados Partes tienen la responsabilidad de proteger el patrimonio cultural subacuático en la 
Zona, de conformidad con la presente Convención y con el Artículo 149 de la Convención de las Naciones Unidas sobre el Derecho del Mar. En consecuencia, cuando un nacional de un Estado Parte o un buque que enarbole su pabellón descubra patrimonio cultural subacuático situado en la Zona, o tenga la intención de efectuar una actividad dirigida a dicho patrimonio, ese Estado Parte exigirá que su nacional o el capitán del buque le informe de ese descubrimiento o de esa actividad.

2. Los Estados Partes notificarán al Director General y al Secretario General de la Autoridad Internacional de los Fondos Marinos los descubrimientos o actividades dirigidas al patrimonio cultural subacuático de que hayan sido informados.

3. El Director General comunicará sin demora a todos los Estados Partes cualquier información de este tipo suministrada por los Estados Partes.

4. Un Estado Parte podrá declarar al Director General su interés en ser consultado sobre cómo asegurar la protección efectiva de ese patrimonio cultural subacuático. Dicha declaración deberá fundarse en un vínculo verificable con ese patrimonio cultural subacuático, habida cuenta en particular de los derechos preferentes de los Estados de origen cultural, histórico o arqueológico.

Artículo 12. Protección del patrimonio cultural subacuático en la Zona

I.No se concederá autorización alguna para una actividad dirigida al patrimonio cultural subacuático situado en la Zona, salvo lo dispuesto en el preente artículo.

2. El Director General invitará a todos los Estados Partes que hayan declarado un interés en virtud del párrafo 4 del Artículo II a efectuar consultas sobre la mejor manera de proteger el patrimonio cultural subacuático, y a designar un Estado Parte para coordinar esas consultas como "Estado Coordinador". El Director General invitará asimismo a la Autoridad Internacional de los Fondos Marinos a participar en esas consultas.

3. Todos los Estados Partes podrán adoptar todas las medidas viables conforme a la presente Convención, de ser necesario, antes de efectuar consultas, con el fin de impedir todo peligro inmediato para el patrimonio cultural subacuático, ya sea ocasionado por la actividad humana o por cualquier otra causa, incluido el saqueo.

\section{El Estado Coordinador:}

a) pondrá en práctica las medidas de protección que hayan sido acordadas por los Estados que participen en la consulta, que incluyen al Estado Coordinador, a menos que los Estados que participen en la consulta, que incluyen al Estado Coordinador, acuerden que otro Estado Parte pondrá en práctica dichas medidas; $y$

b) expedirá todas las autorizaciones necesarias con respecto a las medidas así acordadas de conformidad con la presente Convención, a menos que los Estados que participen en la consulta, que incluyen al Estado Coordinador, acuerden que otro Estado Parte expedirá dichas autorizaciones.

5. El Estado Coordinador podrá realizar toda investigación preliminar que resulte necesaria en el patrimonio cultural subacuático y expedirá todas las autorizaciones necesarias a tal fin, y transmitirá sin demora los resultados de tal investigación al Director General quien, a su vez, comunicará esas informaciones a los demás Estados Partes.

6. Al coordinar las consultas, adoptar medidas, realizar una investigación preliminar y/o expedir autorizaciones en virtud del presente artículo, el Estado Coordinador actuará en beneficio de toda la humanidad, en nombre de todos los Estados Partes. Se prestará especial atención a los derechos preferentes de los Estados de origen cultural, histórico o arqueológico con respecto al patrimonio cultural subacuático de que se trate.

7. Ningún Estado Parte emprenderá ni autorizará actividades dirigidas a un buque o aeronave de Estado en la Zona sin el consentimiento del Estado del pabellón.

\section{Artículo 13. Inmunidad soberana}

Los buques de guerra y otros buques gubernamentales o aeronaves militares que gocen de inmunidad soberana y sean utilizados con fines no comerciales, en el curso normal de sus operaciones, y que no participen en actividades dirigidas al patrimonio cultural subacuático no estarán obligados a comunicar descubrimientos de patrimonio cultural subacuático en virtud de los Artículos 9, 10, II y 12 de la presente Convención. Sin embargo, al adoptar medidas apropiadas que no obstaculicen las operaciones o la capacidad de operación de sus buques de guerra u otros buques gubernamentales o aeronaves militares que gocen de inmunidad soberana y que se utilicen con fines no comerciales, los Estados Partes velarán por que tales buques procedan, en cuanto sea razonable y posible, de manera compatible con lo dispuesto en los Artículos 9, 10, 11 y 12 de la presente Convención.

\section{Artículo 14. Control de entrada en el territorio, comercio y posesión}

Los Estados Partes tomarán medidas para impedir la entrada en su territorio, el comercio y la posesión de patrimonio cultural subacuático exportado ilícitamente y/o recuperado, cuando tal recuperación sea contraria a la presente Convención.

\section{Artículo 15. No utilización de las zonas bajo jurisdicción de los Estados Partes}

Los Estados Partes adoptarán medidas para prohibir

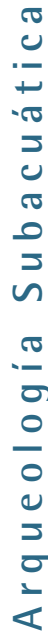

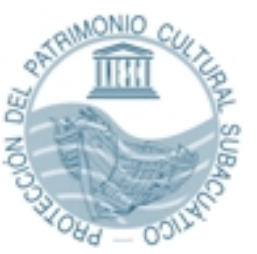


la utilización de su territorio, incluidos sus puertos marítimos y sus islas artificiales, instalaciones y estructuras bajo su jurisdicción o control exclusivos, en apoyo de cualquier actividad dirigida al patrimonio cultural subacuático que no esté de conformidad con la presente Convención.

\section{Artículo 16. Medidas referentes a los nacionales y los bu- ques}

Los Estados Partes adoptarán todas las medidas viables para asegurar que sus nacionales y los buques que enarbolan su pabellón no procedan a ninguna actividad dirigida al patrimonio cultural subacuático que no esté de conformidad con la presente Convención.

\section{Artículo 17. Sanciones}

I. Cada Estado Parte impondrá sanciones respecto de las infracciones de las medidas que haya adoptado para poner en práctica la presente Convención.

2. Las sanciones aplicables respecto de las infracciones deberán ser suficientemente severas para hacer efectivo el cumplimiento de la presente Convención y desalentar la comisión de infracciones cualquiera que sea el lugar, y deberán privar a los infractores de los beneficios derivados de sus actividades ilícitas.

3. Los Estados Partes cooperarán para asegurar el cumplimiento de las sanciones impuestas en virtud del presente artículo.

\section{Artículo 18. Incautación y disposición de patrimonio cultu- ral subacuático}

I. Cada Estado Parte adoptará medidas destinadas a la incautación de elementos de patrimonio cultural subacuático situado en su territorio, que haya sido recuperado de una manera no conforme con la presente Convención.

2. Cada Estado Parte registrará, protegerá y tomará todas las medidas que resulten razonables para la estabilización de patrimonio cultural subacuático incautado en virtud de la presente Convención.

3. Cada Estado Parte notificará toda incautación de patrimonio cultural subacuático realizada en virtud de la presente Convención al Director General de la UNESCO y a cualquier otro Estado que tenga un vínculo verificable, en especial de índole cultural, histórica o arqueológica con el patrimonio cultural subacuático de que se trate.

4. Un Estado Parte que haya incautado patrimonio cultural subacuático velará por darle una disposición acorde con el bien general, tomando en consideración los imperativos de conservación e investigación, la necesidad de reunir las colecciones dispersas, así como la necesidad del acceso, la exposición y educa- ción públicos y los intereses de cualquier Estado que tenga un vínculo verificable, en especial de índole cultural, histórica o arqueológica con el patrimonio cultural subacuático de que se trate.

Artículo 19. Cooperación y utilización compartida de la información

I. Los Estados Partes deberán cooperar entre sí y prestarse asistencia para velar por la protección y gestión del patrimonio cultural subacuático en virtud de la presente Convención, incluyendo cuando sea posible, la colaboración en la exploración, la excavación, la documentación, la conservación, el estudio y la presentación de ese patrimonio.

2. En la medida en que sea compatible con los objetivos de esta Convención, cada Estado Parte se compromete a compartir con otros Estados Partes información en relación con el patrimonio cultural subacuático, incluida la referente al descubrimiento de ese patrimonio, su localización, el patrimonio extraído o recuperado de manera contraria a esta Convención o que viole otras disposiciones del derecho internacional, la metodología y las técnicas científicas pertinentes y la evolución del derecho aplicable al patrimonio de que se trate.

3. Toda información compartida entre Estados Partes, o entre la UNESCO y Estados Partes, relativa al descubrimiento o localización de patrimonio cultural subacuático se mantendrá con carácter confidencial y se comunicará exclusivamente a las autoridades competentes de los Estados Partes, en la medida en que sus respectivas legislaciones nacionales lo permitan, y en tanto la divulgación de esa información pueda poner en peligro o amenazar de alguna manera la preservación de ese patrimonio cultural subacuático.

4. Cada Estado Parte adoptará todas las medidas viables, para difundir información sobre el patrimonio cultural subacuático extraído o recuperado de manera contraria a esta Convención o en violación de otras disposiciones del derecho internacional, incluyendo, cuando sea posible, la utilización de bases de datos internacionales apropiadas.

\section{Artículo 20. Sensibilización del público}

Cada Estado Parte adoptará todas las medidas viables para que el público tome conciencia del valor y de la relevancia del patrimonio cultural subacuático, así como de la importancia que tiene su protección en virtud de esta Convención.

\section{Artículo 21. Formación en arqueología subacuática}

Los Estados Partes cooperarán para impartir una formación en arqueología subacuática, en las técnicas de preservación del patrimonio cultural subacuático y, conforme a los términos acordados, en la transferen- 
cia de tecnologías relacionadas con el patrimonio cultural subacuático.

\section{Artículo 22. Autoridades competentes}

I. A fin de velar por la correcta puesta en práctica de esta Convención, los Estados Partes establecerán autoridades competentes o, en su caso, reforzarán las ya existentes para que puedan elaborar, mantener y actualizar un inventario del patrimonio cultural subacuático y garantizar eficazmente la protección, la conservación, la presentación y la gestión del patrimonio cultural subacuático, así como la investigación y educación.

2. Los Estados Partes comunicarán al Director General el nombre y la dirección de sus autoridades competentes en materia de patrimonio cultural subacuático.

\section{Artículo 23. Reunión de los Estados Partes}

I.El Director General convocará una Reunión de los Estados Partes en el plazo de un año contado a partir de la entrada en vigor de la presente Convención y ulteriormente por lo menos una vez cada dos años. A petición de una mayoría de los Estados Partes, el Director General convocará una Reunión Extraordinaria de los Estados Partes.

2. La Reunión de los Estados Partes decidirá sobre sus funciones y responsabilidades.

3. La Reunión de los Estados Partes aprobará su propio Reglamento.

4. La Reunión de los Estados Partes podrá crear un Consejo Consultivo Científico y Técnico compuesto por expertos designados por los Estados Partes, con la debida atención al principio de distribución geográfica equitativa y a la conveniencia de un equilibrio entre los sexos.

5. El Consejo Consultivo Científico y Técnico prestará la asistencia adecuada a la Reunión de los Estados Partes sobre las cuestiones de índole científica y técnica relacionadas con la puesta en práctica de las Normas.

\section{Artículo 24. Secretaría de la Convención}

I.El Director General será responsable de la Secretaría de la presente Convención.

2. Las funciones de la Secretaría incluirán las siguientes tareas:

a) organizar las Reuniones de los Estados Partes previstas en el párrafo I del Artículo 23; y

b) prestar asistencia a los Estados Partes en la puesta en práctica de las decisiones de las Reuniones de los Estados Partes.

\section{Artículo 25. Solución pacífica de controversias}

I. Cualquier controversia entre dos o más Estados Partes acerca de la interpretación o la aplicación de la presente Convención deberá ser objeto de negociaciones de buena fe o de otros medios de solución pacífica de su elección.

2. Si dichas negociaciones no resolvieran la controversia en un plazo razonable, los Estados Partes de que se trate podrán, de común acuerdo, someterla a la mediación de la UNESCO.

3. Si no se recurriera a la mediación o si ésta no resolviera las controversias, las disposiciones relativas a la solución de controversias enunciadas en la Parte $\mathrm{XV}$ de la Convención de las Naciones Unidas sobre el Derecho del Mar se aplicarán mutatis mutandis a toda controversia entre Estados Partes en la presente Convención respecto de la interpretación o la aplicación de esta Convención, independientemente de que sean o no también Partes en la Convención de las Naciones Unidas sobre el Derecho del Mar.

4. Todo procedimiento escogido por un Estado Parte en la presente Convención y en la Convención de las Naciones Unidas sobre el Derecho del Mar, en virtud del Artículo 287 de esta última, se aplicará a la solución de controversias en virtud del presente artículo, a menos que ese Estado Parte, al ratificar, aceptar o aprobar la presente Convención o al adherirse a ella, o en cualquier momento ulterior, haya elegido otro procedimiento en virtud del Artículo 287 para la solución de controversias derivadas de la presente Convención.

5. Al ratificar, aceptar, aprobar la presente Convención o adherirse a ella, o en cualquier momento ulterior, un Estado Parte en la presente Convención que no sea Parte en la Convención de las Naciones Unidas sobre el Derecho del Mar podrá elegir libremente, mediante una declaración escrita, uno o varios de los medios enunciados en el párrafo I del Artículo 287 de la Convención de las Naciones Unidas sobre el Derecho del Mar para la solución de las controversias con arreglo al presente artículo. El Artículo 287 se aplicará a esa declaración así como a toda controversia en la que ese Estado sea Parte y que no esté amparada por una declaración en vigor. A efectos de conciliación y arbitraje, de conformidad con los Anexos V y VII de la Convención de las Naciones Unidas sobre el Derecho del Mar, ese Estado estará habilitado para designar conciliadores y árbitros que se incluirán en las listas mencionadas en el Artículo 2 del Anexo $\vee$ y en el Artículo 2 del Anexo VII para la solución de las controversias derivadas de la presente Convención.

\section{Artículo 26. Ratificación, aceptación, aprobación o adhe- sión}

I. La presente Convención estará sujeta a la ratificación,

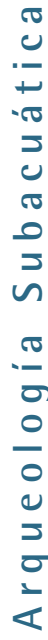

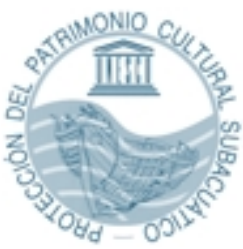

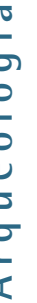


aceptación o aprobación de los Estados Miembros de la UNESCO.

2. La presente Convención estará sujeta a la adhesión:

a) de los Estados que no sean miembros de la UNESCO pero que sean miembros de las $\mathrm{Na}$ ciones Unidas o de un organismo especializado del sistema de las Naciones Unidas o del Organismo Internacional de Energía Atómica, así como de los Estados Partes en el Estatuto de la Corte Internacional de Justicia, y de cualquier otro Estado al que la Conferencia General de la UNESCO haya invitado a adherirse a la presente Convención;

b) de los territorios que gocen de plena autonomía interna reconocida como tal por las Naciones Unidas, pero que no hayan alcanzado la plena independencia de conformidad con la Resolución I5 I 4 (XV) de la Asamblea General, y que tengan competencia sobre las materias regidas por esta Convención, incluida la de celebrar tratados en relación con ellas.

3. Los instrumentos de ratificación, aceptación, aprobación o adhesión serán depositados ante el Director General.

\section{Artículo 27. Entrada en vigor}

La Convención entrará en vigor tres meses después de la fecha en que haya sido depositado el vigésimo instrumento a que se refiere el Artículo 26, pero únicamente respecto de los veinte Estados o territorios que hayan depositado sus instrumentos. Entrará en vigor para cualquier otro Estado o territorio tres meses después de la fecha en que dicho Estado o territorio haya depositado su instrumento.

\section{Artículo 28. Declaración relativa a las aguas continentales}

Al ratificar, aceptar, aprobar esta Convención o adherirse a ella o en cualquier momento ulterior, todo Estado o territorio podrá declarar que las Normas se aplicarán a sus aguas continentales que no sean de carácter marítimo.

\section{Artículo 29. Limitación del ámbito de aplicación geográfico}

Al ratificar, aceptar, aprobar la presente Convención o adherirse a ella, un Estado o territorio podrá declarar ante el depositario que la presente Convención no se aplicará a determinadas partes de su territorio, sus aguas interiores, aguas archipelágicas o mar territorial e indicará en esa declaración las razones que la motivan. En la medida de lo posible, y tan pronto como pueda, el Estado deberá reunir las condiciones necesarias para que la presente Convención se aplique a las zonas especificadas en su declaración; a esos efectos, y en cuanto haya reunido esas condiciones, retirará también total o parcialmente su declaración.

\section{Artículo 30. Reservas}

Salvo lo dispuesto en el Artículo 29, no se podrán formular reservas a la presente Convención.

\section{Artículo 31. Enmiendas}

I. Un Estado Parte podrá proponer enmiendas a esta Convención mediante comunicación dirigida por escrito al Director General. El Director General transmitirá la comunicación a todos los Estados Partes. Si dentro de los seis meses siguientes a la fecha de envío de la comunicación, la mitad por lo menos de los Estados Partes responde favorablemente a esa petición, el Director General presentará dicha propuesta para examen y posible aprobación de la siguiente Reunión de los Estados Partes.

2. Las enmiendas serán aprobadas por una mayoría de dos tercios de los Estados Partes presentes y votantes.

3. Una vez aprobadas, las enmiendas a esta Convención deberán ser objeto de ratificación, aceptación, aprobación o adhesión por los Estados Partes.

4. La enmienda a esta Convención entrarán en vigor únicamente para los Estados Partes que las hayan ratificado, aceptado, aprobado o que se hayan adherido a ellas tres meses después de que dos tercios de los Estados Partes hayan depositado los instrumentos mencionados en el párrafo 3 del presente artículo. A partir de esa fecha, la enmienda entrará en vigor para cada Estado Parte o territorio que la ratifique, acepte, apruebe o se adhiera a ella tres meses después de la fecha en que esa Parte haya depositado su instrumento de ratificación, aceptación, aprobación o adhesión.

5. Un Estado o territorio que llegue a ser Parte en esta Convención después de la entrada en vigor de enmiendas efectuadas de conformidad con el párrafo 4 del presente artículo y que no manifieste una intención diferente, será considerado:

a) Parte en esta Convención así enmendada; y

b) Parte en la Convención no enmendada con respecto a todo Estado Parte que no esté obligado por la enmienda.

\section{Artículo 32. Denuncia}

I. Un Estado Parte podrá denunciar esta Convención mediante notificación dirigida por escrito al Director General.

2. La denuncia surtirá efecto doce meses después de la fecha de recepción de la notificación, a menos que en ella se especifique una fecha ulterior.

3. La denuncia no afectará en modo alguno el deber de los Estados Partes de cumplir todas las obligaciones contenidas en la presente Convención a las que es- 
tén sometidos en virtud del derecho internacional con independencia de esta Convención.

\section{Artículo 33. Las Normas}

Las Normas que figuran en el Anexo de esta Convención son parte integrante de ella y, salvo disposición expresa en contrario, cualquier referencia a esta Convención constituye asimismo una referencia a las Normas.

\section{Artículo 34. Registro en las Naciones Unidas}

Con arreglo a lo dispuesto en el Artículo 102 de la Carta de las Naciones Unidas, la presente Convención deberá ser registrada en la Secretaría de las Naciones Unidas a petición del Director General.

\section{Artículo 35. Textos auténticos}

Esta Convención se ha redactado en árabe, chino, español, francés, inglés y ruso, siendo los seis textos igualmente auténticos.

\section{ANEXO}

Normas relativas a las actividades dirigidas al patrimonio cultural subacuático

\section{Principios generales}

Norma I. La conservación in situ será considerada la opción prioritaria para proteger el patrimonio cultural subacuático. En consecuencia, las actividades dirigidas al patrimonio cultural subacuático se autorizarán únicamente si se realizan de una manera compatible con su protección y, a reserva de esa condición, podrán autorizarse cuando constituyan una contribución significativa a la protección, el conocimiento o el realce de ese patrimonio.

Norma 2. La explotación comercial de patrimonio cultural subacuático que tenga por fin la realización de transacciones, la especulación o su dispersión irremediable es absolutamente incompatible con una protección y gestión correctas de ese patrimonio. El patrimonio cultural subacuático no deberá ser objeto de transacciones ni de operaciones de venta, compra o trueque como bien comercial.

\section{No cabrá interpretar que esta norma prohíba:}

a) la prestación de servicios arqueológicos profesionales o de servicios conexos necesarios cuya índole y finalidad sean plenamente conformes con la presente Convención, y tengan la autorización de las autoridades competentes;

b) el depósito de patrimonio cultural subacuático recu- perado en el marco de un proyecto de investigación ejecutado de conformidad con esta Convención, siempre que dicho depósito no vulnere el interés científico o cultural, ni la integridad del material recuperado, ni dé lugar a su dispersión irremediable, esté de conformidad con lo dispuesto en las Normas 33 y 34 y tenga la autorización de las autoridades competentes.

Norma 3. Las actividades dirigidas al patrimonio cultural subacuático no deberán perjudicarlo más de lo que sea necesario para los objetivos del proyecto.

Norma 4. Las actividades dirigidas al patrimonio cultural subacuático deberán servirse de técnicas y métodos de exploración no destructivos, que deberán preferirse a la recuperación de objetos. Si para llevar a cabo estudios cientíicos o proteger de modo definitivo el patrimonio cultural subacuático fuese necesario realizar operaciones de extracción o recuperación, las técnicas y los métodos empleados deberán ser lo menos dañinos posible y contribuir a la preservación de los vestigios.

Norma 5. Las actividades dirigidas al patrimonio cultural subacuático evitarán perturbar innecesariamente los restos humanos o los sitios venerados.

Norma 6. Las actividades dirigidas al patrimonio cultural subacuático se reglamentarán estrictamente para que se registre debidamente la información cultural, histórica y arqueológica.

Norma 7. Se fomentará el acceso del público al patrimonio cultural subacuático in situ, salvo en los casos en que éste sea incompatible con la protección y la gestión del sitio.

Norma 8. Se alentará la cooperación internacional en la realización de actividades dirigidas al patrimonio cultural subacuático con objeto de propiciar intercambios eficaces de arqueólogos y demás especialistas competentes y de emplear mejor sus capacidades.

\section{Plan del proyecto}

Norma 9. Antes de iniciar cualquier actividad dirigida al patrimonio cultural subacuático se elaborará el proyecto correspondiente, cuyo plan se presentará a las autoridades competentes para que lo autoricen, previa revisión por los pares.

\section{Norma 10. El plan del proyecto incluirá:}

a) una evaluación de los estudios previos o preliminares;

b) el enunciado y los objetivos del proyecto;

c) la metodología y las técnicas que se utilizarán;

d) el plan de financiación;

e) el calendario previsto para la ejecución del proyecto; f) la composición del equipo, las calificaciones, las funciones y la experiencia de cada uno de sus integrantes; g) planes para los análisis y otras actividades que se realizarán después del trabajo de campo;

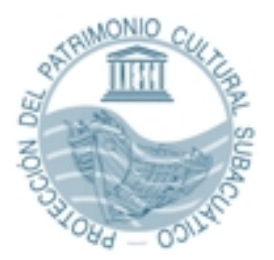


h) un programa de conservación de los objetos y del sitio, en estrecha colaboración con las autoridades competentes;

i) una política de gestión y mantenimiento del sitio que abarque toda la duración del proyecto;

j) un programa de documentación;

k) un programa de seguridad;

l) una política relativa al medio ambiente;

m) acuerdos de colaboración con museos y otras instituciones, en particular de carácter científico;

n) la preparación de informes;

o) el depósito de los materiales y archivos, incluido el patrimonio cultural subacuático que se haya extraído; y

p) un programa de publicaciones.

Norma II. Las actividades dirigidas al patrimonio cultural subacuático se realizarán de conformidad con el plan del proyecto aprobado por las autoridades competentes.

Norma 12. Si se hiciesen descubrimientos imprevistos o cambiasen las circunstancias, se revisará y modificará el plan del proyecto con la aprobación de las autoridades competentes.

Norma 13. En caso de emergencia o de descubrimientos fortuitos, las actividades dirigidas al patrimonio cultural subacuático, incluyendo medidas o actividades de conservación por un periodo breve, en particular de estabilización del sitio, podrán ser autorizadas en ausencia de un plan de proyecto, a fin de proteger el patrimonio cultural subacuático.

\section{Labor preliminar}

Norma 14. La labor preliminar mencionada en la Norma 10 a) incluirá una evaluación de la importancia del patrimonio cultural subacuático y su entorno natural y de su vulnerabilidad a posibles perjuicios resultantes del proyecto previsto, así como de las posibilidades de obtener datos que correspondan a los objetivos del proyecto.

Norma 15. La evaluación incluirá además estudios previos de los datos históricos y arqueológicos disponibles, las características arqueológicas y ambientales del sitio y las consecuencias de cualquier posible intrusión en la estabilidad a largo plazo del patrimonio cultural subacuático objeto de las actividades.

\section{Objetivos, metodología y técnicas del proyecto}

Norma 16. La metodología se deberá ajustar a los objetivos del proyecto y las técnicas utilizadas deberán ser lo menos perjudiciales posible.

\section{Financiación}

Norma 17. Salvo en los casos en que la protección del patrimonio cultural subacuático revista carácter de urgencia, antes de iniciar cualquier actividad dirigida al mismo se deberá contar con la financiación suficiente para cumplir todas las fases previstas en el plan del proyecto, incluidas la conservación, la documentación y la preservación del material recuperado, así como la preparación y la difusión de los informes.

Norma 18. En el plan del proyecto se demostrará la capacidad de financiar el proyecto hasta su conclusión, por ejemplo, mediante la obtención de una garantía.

Norma 19. El plan del proyecto incluirá un plan de emergencia que garantice la conservación del patrimonio cultural subacuático y la documentación de apoyo en caso de interrumpirse la financiación prevista.

\section{Duración del proyecto - Calendario}

Norma 20. Antes de iniciar cualquier actividad dirigida al patrimonio cultural subacuático se preparará el calendario correspondiente para garantizar de antemano el cumplimiento de todas las fases del proyecto, incluidas la conservación, la documentación y la preservación del patrimonio cultural subacuático recuperado, así como la preparación y la difusión de los informes.

Norma 21. El plan del proyecto incluirá un plan de emergencia que garantice la conservación del patrimonio cultural subacuático y la documentación de apoyo en caso de interrupción o conclusión del proyecto.

\section{Competencia y calificaciones}

Norma 22. Sólo se efectuarán actividades dirigidas al patrimonio cultural subacuático bajo la dirección y el control y con la presencia continuada de un arqueólogo subacuático cualificado que tenga la competencia cientííca adecuada a la índole del proyecto.

Norma 23. Todos los miembros del equipo del proyecto deberán estar cualificados y haber demostrado una competencia adecuada a la función que desempeñarán en el proyecto.

\section{Conservación y gestión del sitio}

Norma 24. En el programa de conservación estarán previstos el tratamiento de los restos arqueológicos durante las actividades dirigidas al patrimonio cultural subacuático, en el curso de su traslado y a largo plazo. La conservación se efectuará de conformidad con las normas profesionales vigentes.

Norma 25. En el programa de gestión del sitio estarán previstas la protección y la gestión in situ del patrimonio cultural subacuático durante el trabajo de campo y una vez que éste haya concluido. El programa abarcará actividades de información pública, medidas adecuadas para la estabilización del sitio, su control sistemático y su protección de las intrusiones. 


\section{Documentación}

Norma 26. En el marco del programa de documentación, se documentarán exhaustivamente las actividades dirigidas al patrimonio cultural subacuático incluyendo un informe sobre la marcha de las actividades, elaborado de conformidad con las normas profesionales vigentes en materia de documentación arqueológica.

Norma 27. La documentación incluirá como mínimo un inventario detallado del sitio, con indicación de la procedencia del patrimonio cultural subacuático desplazado o retirado en el curso de las actividades dirigidas al mismo, apuntes sobre el trabajo de campo, planos, dibujos, secciones, fotografías o registros en otros medios.

\section{Seguridad}

Norma 28. Se preparará un plan de seguridad adecuado para velar por la seguridad y la salud de los integrantes del equipo y de terceros, que esté en conformidad con las normativas legales y profesionales en vigor.

\section{Medio ambiente}

Norma 29. Se preparará una política relativa al medio ambiente adecuada para velar por que no se perturben indebidamente los fondos marinos o la vida marina.

\section{Informes}

Norma 30. Se presentarán informes sobre el desarrollo de los trabajos, así como informes finales de conformidad con el calendario establecido en el plan del proyecto y se depositarán en los registros públicos correspondientes.

Norma 31. Los informes incluirán:

a) una descripción de los objetivos;

b) una descripción de las técnicas y los métodos utilizados;

c) una descripción de los resultados obtenidos;

d) documentación gráfica y fotográfica esencial, sobre todas las fases de la actividad;

e) recomendaciones relativas a la conservación y preservación del sitio y del patrimonio cultural subacuático que se haya extraído; y

f) recomendaciones para actividades futuras.

\section{Conservación de los archivos del proyecto}

Norma 32. Las disposiciones sobre la conservación de los archivos del proyecto se acordarán antes de iniciar cualquier actividad y se harán constar en el plan del proyecto.

Norma 33. Los archivos del proyecto, incluido cualquier patrimonio cultural subacuático que se haya extraído y una copia de toda la documentación de apoyo, se conservarán, en la medida de lo posible, juntos e intactos en forma de colección, de tal manera que los especialistas y el público en general puedan tener acceso a ellos y que pueda procederse a la preservación de los archivos. Ello debería hacerse lo más rápidamente posible y, en cualquier caso, no después de transcurridos diez años desde la conclusión del proyecto, siempre que ello sea compatible con la conservación del patrimonio cultural subacuático.

Norma 34. La gestión de los archivos del proyecto se hará conforme a las normas profesionales internacionales, y estará sujeta a la autorización de las autoridades competentes.

\section{Difusión}

Norma 35. En los proyectos se preverán actividades de educación y de difusión al público de los resultados del proyecto, según proceda.

Norma 36. La síntesis final de cada proyecto:

a) se hará pública tan pronto como sea posible, habida cuenta de la complejidad del proyecto y el carácter confidencial o delicado de la información; y

b) se depositará en los registros públicos correspondientes.

Lo anterior es el texto auténtico de la Convención aprobada en buena y debida forma por la Conferencia General de la Organización de las Naciones Unidas para la Educación, la Ciencia y la Cultura, en su trigésimo primera reunión, celebrada en París y terminada el tres de noviembre de 2001 .
I. Véase Pérez del Campo, "Hacia una Convención Internacional para la protección del Patrimonio Histórico Subacuático". PH. Boletín del Instituto Andaluz del Patrimonio Histórico, 26 (abril 1999), pp. 99-108)

2. Remitimos al lector interesado por el tema a las propias publicaciones de la UNESCO. Concretamente en la página web $<$ http://www.fuentesunesco.org> encontrará una amplia documentación sobre los antecedentes de esta Convención y la problemática de los caza tesoros frente a la protección del patrimonio cultural sumergido.
3. Según fuentes de la UNESCO (véase Williams, S. "Patrimonio submarino: herencia con mar de fondo". Fuentes UNESCO,87, Febrero 1997, pp. 7-8), la casa de subastas Christie's se ha convertido en la especialista mundial de lo que denominan materiales conseguidos legalmente o bajo licencia procedente de pecios históricos. En 1986 obtuvo 16 millones de dólares de beneficios en la venta de porcelanas chinas y lingotes de oro procedentes del cargamento del Nankim, un barco de pabellón holandés hundido en 1752 al sur del mar de China. Igualmente, la venta de porcelanas del cargamento del Vung Tao, hundido en la costa sur de Vietnam, le supusieron ganancias de 7,2 millones de dólares.

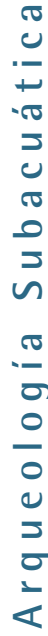

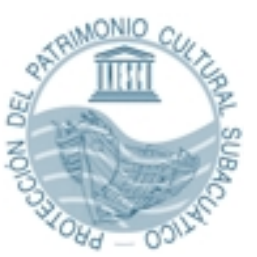

